\title{
Blood pressure homeostasis is maintained by a P311-TGF- $\beta$ axis
}

\author{
Kameswara Rao Badri, ${ }^{1}$ Ming Yue, ${ }^{1}$ Oscar A. Carretero, ${ }^{2}$ Sree Latha Aramgam, ${ }^{1}$ Jun Cao, ${ }^{1}$ \\ Stephen Sharkady, ${ }^{3}$ Gene H. Kim, ${ }^{4}$ Gregory A. Taylor, ${ }^{5}$ Kenneth L. Byron, ${ }^{6}$ and Lucia Schuger ${ }^{1}$

\begin{abstract}
1Department of Pathology, The University of Chicago, Chicago, Illinois, USA. ${ }^{2}$ Hypertension and Vascular Research Division, Department of Internal Medicine, Henry Ford Health System, Detroit, Michigan, USA. ${ }^{3}$ Department of Biochemistry, Lake Erie College of Osteopathic Medicine at Seton Hill, Greensburg, Pennsylvania, USA. ${ }^{4}$ Department of Medicine, Section of Cardiology, The University of Chicago, Chicago, Illinois, USA. ${ }^{5}$ Departments of Medicine, Molecular Genetics and Microbiology, and Immunology, Division of Geriatrics, and Center for the Study of Aging and Human Development, Duke University Medical Center, and GRECC, VA Medical Center, Durham, North Carolina, USA.

${ }^{6}$ Department of Molecular Pharmacology and Experimental Therapeutics, Loyola University Chicago, Maywood, Illinois, USA.
\end{abstract}

\begin{abstract}
P311 is an 8-kDa intracellular protein that is highly conserved across species and is expressed in the nervous system as well as in vascular and visceral smooth muscle cells. P311-null $\left(P 311^{-/}\right)$mice display learning and memory defects, but alterations in their vasculature have not been previously described. Here we report that $P 311^{-/-}$mice are markedly hypotensive with accompanying defects in vascular tone and VSMC contractility. Functional abnormalities in $P 311^{-/-}$mice resulted from decreased total and active levels of TGF- $\beta 1$, TGF- $\beta 2$, and TGF- $\beta 3$ that arise as a specific consequence of decreased translation. Vascular hypofunctionality was fully rescued in vitro and in vivo by exogenous TGF- $\beta 1$-TGF- $\beta 3$. Conversely, $P 311$-transgenic $\left(P 311^{T G}\right)$ mice had elevated levels of TGF- $\beta 1$-TGF- $\beta 3$ and subsequent hypertension. Consistent with findings attained in mouse models, arteries recovered from hypertensive human patients displayed increased P311 expression. Thus, we identified P311 as the first protein known to modulate TGF- $\beta$ translation and the first pan-regulator of TGF- $\beta$ expression under steady-state conditions. Together, our findings point to P311 as a critical blood pressure regulator and establish a potential link between P311 expression and the development of hypertensive disease.
\end{abstract}

\section{Introduction}

P311 is an 8-kDa intracellular protein that is highly conserved across species and is normally expressed in the nervous system and in vascular and visceral smooth muscle beds. In addition, P311 is detected in myofibroblasts (1), at the invading edge of glioblastomas (2), in regenerating nerve and lung $(3,4)$, and in hypertrophic scars (5). P311 has been implicated in myofibroblast differentiation as well as nerve and lung regeneration $(3,4)$. Although it neither belongs to any established protein family nor possesses signature motifs that suggest function, P311 features a conserved PEST (rich in proline $[\underline{\mathrm{P}}]$, glutamic acid $[\underline{\mathrm{D}}]$, aspartic acid $[\underline{\mathrm{E}}]$, and serine $[\underline{\mathrm{S}}]$ or threonine $[\underline{\mathrm{T}}]$ )-like amino acid sequence at the $\mathrm{N}$ terminus (6). PEST motifs were originally identified in short-lived proteins as targets for ubiquitin-proteasome degradation (7) and subsequently found to mediate protein-protein interactions and activation (8-14). Although deletion of P311 in mice results in no overt phenotype (15), $P 311^{-/-}$mice display learning and memory defects, consistent with the presence of P311 in the nervous system $(15,16)$.

TGF- $\beta$ s are multifunctional growth factors capable of inducing a spectrum of cellular events, including proliferation, cell cycle arrest, differentiation, programmed cell death, and stimulation of matrix deposition (17-19). TGF- $\beta$ s are synthesized as a large homodimeric precursor (pro-TGF- $\beta$ ) that is cleaved into mature

Authorship note: Kameswara Rao Badri and Ming Yue contributed equally to this work.

Conflict of interest: The authors have declared that no conflict of interest exists.

Note regarding evaluation of this manuscript: Manuscripts authored by scientists associated with Duke University, The University of North Carolina at Chapel Hill, Duke-NUS, and the Sanford-Burnham Medical Research Institute are handled not by members of the editorial board but rather by the science editors, who consult with selected external editors and reviewers.

Citation for this article: J Clin Invest. 2013;123(10):4502-4512. doi:10.1172/JCI69884.
TGF- $\beta$ and latent-asssociated protein (LAP), which remain noncovalently associated $(20,21)$. Before TGF- $\beta$ s can exert their biological effects, they must dissociate from LAP in order to become active $(20,21)$. Active TGF- $\beta$ s signal through TGF- $\beta$ receptors I and II and the transcriptional coregulators Smad2 and Smad3 (22-24). Upon phosphorylation (i.e., activation), Smad 2 and Smad3 bind to Smad4, translocate to the nucleus, and bind to the CAGA box (found in the promoters of multiple TGF- $\beta$-responsive genes; refs. $25,26)$ to activate their transcription $(22-24)$. Smad-independent pathways had been also identified $(22,23)$.

Because P311 is also expressed at high levels in VSMCs $(1,6)$, we explored its potential role within the systemic vasculature. Here, we found that $P 311^{-/-}$mice were markedly hypotensive, with accompanying defects in vascular tone and VSMC contractility. Functional abnormalities in $P 311^{-/-}$mice resulted from decreased translation of TGF- $\beta$, which decreased the level and activity of TGF- $\beta$ s. Conversely, mice overexpressing P311 showed an elevation in level and activity of TGF- $\beta$ s as well as systemic hypertension. Consistent with these findings, arteries from hypertensive humans displayed increased P311 expression. In summary, our studies identified P311 as the first regulator of TGF- $\beta$ s translation with a critical role in blood pressure control.

\section{Results}

$P 311^{-1-}$ mice have systemic bypotension and decreased vascular muscle tone, contractility, and RhoA activity. Western blot analysis and immunohistochemistry (IHC) confirmed the presence of P311 in mouse and human VSMCs and its absence in the endothelium and vasculature of $P 311^{-/-}$mice (Supplemental Figure 1, A-D; supplemental material available online with this article; doi:10.1172/JCI69884DS1). P311 expression levels were higher in arteries than in veins (Supplemental Figure 1D). Morphometry 
A
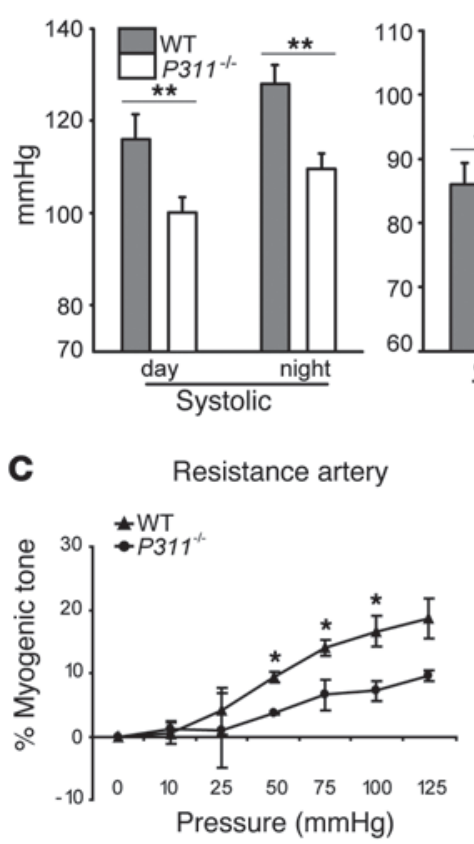

$\mathbf{F}$

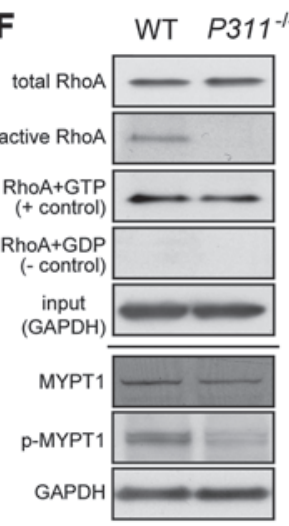

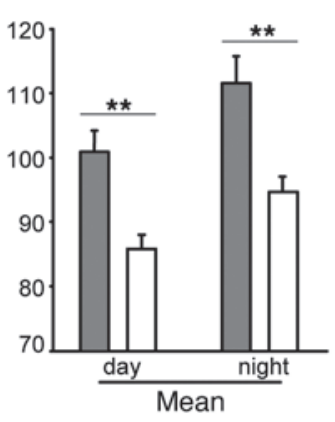

B

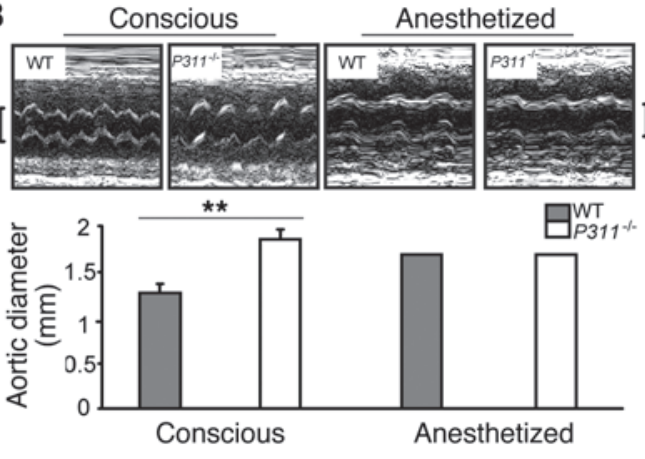

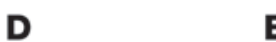

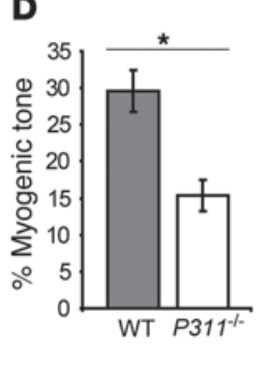

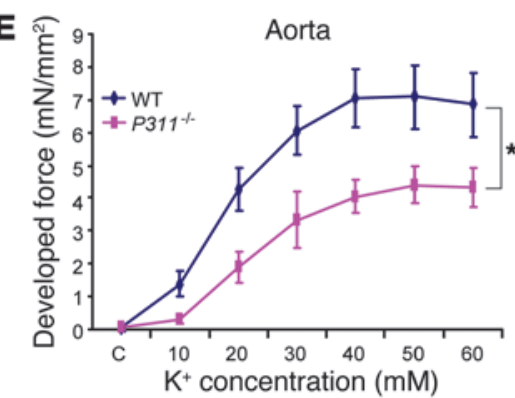

$\mathrm{K}^{+}$concentration $(\mathrm{mM})$

G
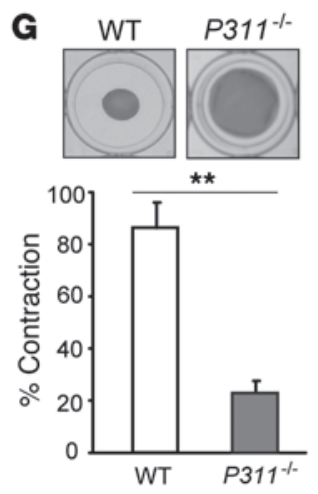

Resistance artery

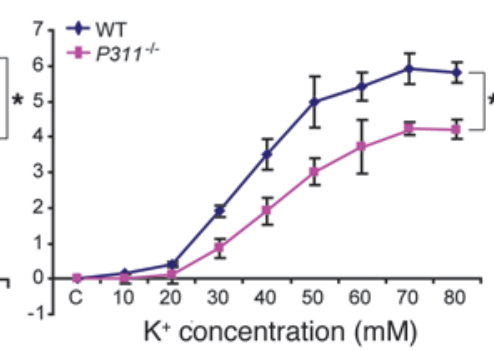

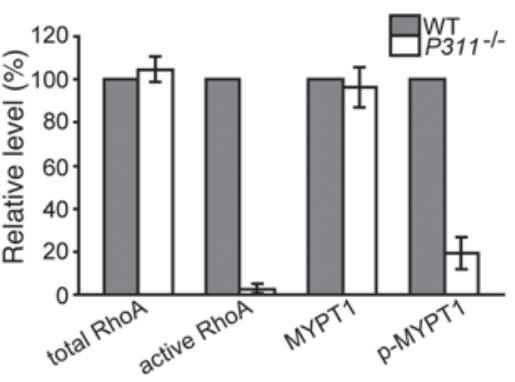

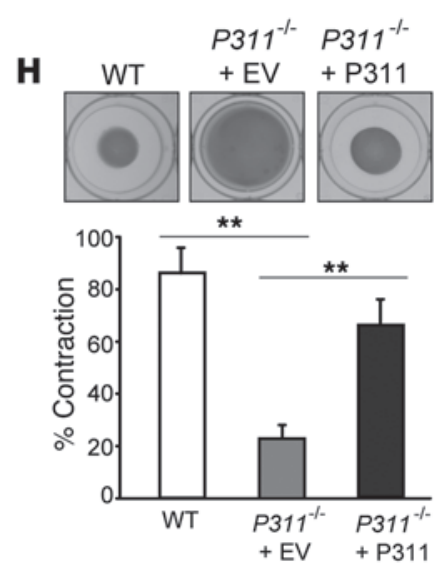

\section{Figure 1}

$P 311^{-1-}$ mice have systemic hypotension and decreased vascular muscle tone, contractility, and RhoA activity. (A) Telemetric determination of systemic blood pressure in WT and $P 311^{-/-}$mice $(n=8$ per group). (B) Echocardiography images of aortic diameter in conscious and anesthetized mice ( $n=8$ per group). Average aortic diameter is also shown. (C) Pressure myographic determination of myogenic tone in resistance arteries ( $n=4$ per group). (D) Myogenic tone of resistance arteries in response to $50 \mathrm{mM} \mathrm{KCl} \mathrm{at} 75 \mathrm{mmHg}$ pressure. (E) Wire myographic determination of the contractile response of aortas ( $n=4$ per group) and resistance arteries $\left(n=3\right.$ per group) to increasing $\mathrm{K}^{+}$ concentration. (F) RhoA activity assay showing active RhoA and Western blot showing total and phosphorylated (p-) MYPT1. Experiments were performed 3 times with similar results. Relative density of Western blot signal in $P 311^{-1-}$ relative to WT mice (analyzed by mylmageAnalysis software; Thermo Scientific) is also shown. (G) Collagen gel contraction by mouse aorta-derived VSMCs. (H) Collagen gel contraction by VSMCs derived from WT and P311-/- aortas, the latter transfected with empty vector (EV) or P311 vector (60\% transfection efficiency). In $\mathbf{G}$ and $\mathbf{H}$, relative contraction was calculated as percent decrease in collagen gel diameter from the original diameter. Gel contraction data were collected from triplicate wells. Data represent mean \pm SD. ${ }^{*} P<0.05$, ${ }^{\star *} P<0.01$, Student's $t$ test.

did not show differences between $P 311^{-/-}$and WT mice (Supplemental Figure 1, E and F). Telemetric determination revealed diurnal systolic and diastolic blood pressures to be $16.5 \pm 3$ and $14 \pm 5$ mmHg lower, respectively, in $P 311^{-1-}$ mice than in WT mice, with slightly increased nocturnal differences (Figure 1A). Echocardiographic studies performed in conscious mice revealed enlarged aortic diameter in $\mathrm{P} 311^{-/}$animals that disappeared under gen- eral anesthesia (Figure 1B). There were no significant differences in other echocardiographic parameters, except for increased cardiac output (Supplemental Figure 2). Together, these findings suggested a decrease in myogenic tone, which was confirmed by pressure myography using resistance arteries $(\sim 150 \mu \mathrm{m}$ in diameter) (Figure 1C and Supplemental Figure 3). Myographic studies on isolated aortas showed decreased contractility in response 

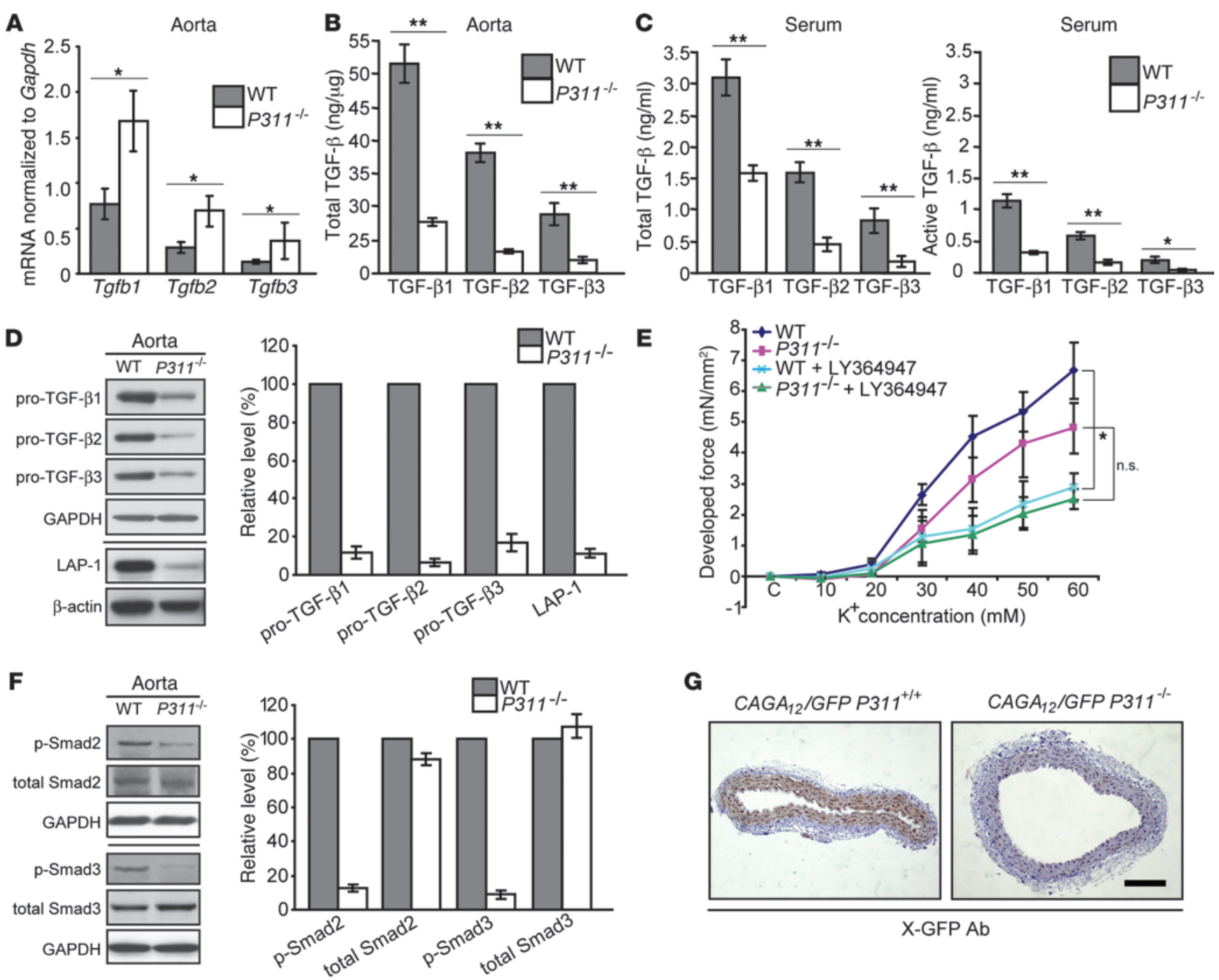

G

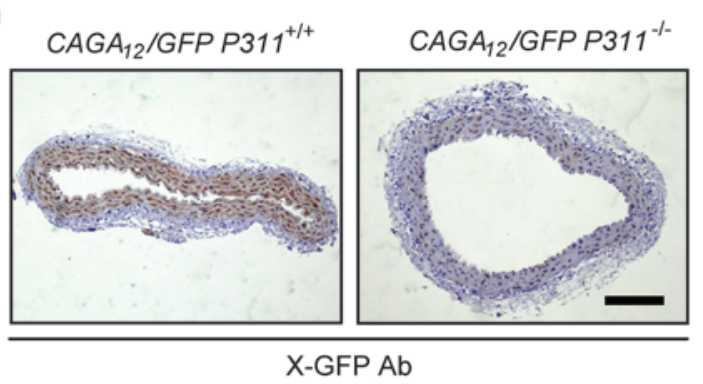

Figure 2

$P 311^{-1-}$ mice have decreased level and activity of TGF- $\beta 1$, TGF- $\beta 2$, and TGF- $\beta 3$ and their preforms, but not in the corresponding mRNAs. (A) Real-time PCR showing Tgfb1, Tgfb2, and Tgfb3 mRNA level in aortas of WT and P311-/- mice. (B) ELISA showing total levels of all 3 TGF- $\beta$ s in aortas. (C) ELISA showing levels of total and active TGF- $\beta$ s in blood serum. (D) Western blots showing expression of pro-TGF- $\beta$ S and LAP-1 in aortas. Relative densities of Western blot signals in P311-/- aortas relative to WT ( $n=15$ per group) are also shown. (E) Myographic determination of the contractile response of TGF- $\beta$ receptor inhibitor-treated $(\mathrm{LY} 364947,100 \mu \mathrm{M})$ resistance arteries to increasing $\mathrm{K}^{+}$concentration $(n=3$ per group). (F) Western blots showing total and phosphorylated Smad2 and Smad3 in aortas ( $n=3$ per group). Relative levels of Smad2 and Smad3 in $P 311^{-/-}$aortas relative to WT are also shown. (G) GFP immunoreactivity (brown staining) in $C A G A_{12} / G F P$ transgenic $P 311^{+/+}$and $P 311^{-/-}$mouse aortas. Scale bar: $100 \mu \mathrm{m}$. Data represent mean \pm SD. ${ }^{\star} P<0.05,{ }^{\star \star} P<0.01$, by 1 -way ANOVA.

to $\mathrm{K}^{+}$depolarization in $P 311^{-/-}$mice (Figure 1E). Consistently, $P 311^{-/-}$resistance arteries also showed decreased contractility in response to $\mathrm{K}^{+}$and to vasoconstriction agonists (norepinephrine, phenylephrine, epinephrine, and angiotensin II), with no difference in the vasodilatation response to hydralazine (Figure $1 \mathrm{E}$ and Supplemental Figure 4, A-E). P311 ${ }^{-/-}$aortas demonstrated decreased RhoA activity, as assessed by RhoA-GTP levels, as well as the phosphorylated fraction of MYPT1 (Figure 1F). Collagen gel contraction assays showed that VSMCs isolated from $P 311^{-1-}$ aortas were less efficient in contracting collagen gels than those derived from WT animals, but their contraction improved after P311 transfection (Figure 1, G and H).
P311-/- mice have decreased level and activity of TGF- $\beta s$, but not of the corresponding $m R N A s$. Although real-time PCR demonstrated upregulated Tgfb1, Tgfb2, and Tgfb3 mRNA levels in aortic tissues isolated from $P 311^{-/-}$mice, ELISA showed that total and active protein levels of the 3 isoforms were severely decreased in tissue extracts and in plasma samples from $P 311^{-/-}$mice (Figure 2, $\mathrm{A}-\mathrm{C})$. Immunoblot analyses demonstrated reduced expression of pro-TGF- $\beta 1$, pro-TGF- $\beta 2$, pro-TGF- $\beta 3$, and LAP-1 (Figure $2 \mathrm{D}$ ). We found that blocking TGF- $\beta$ activity resulted in a decrease in the contractile response of WT and $P 311^{-1-}$ mouse-derived resistance arteries. This decrease was statistically significant only in the WT arteries, which had more TGF- $\beta$ than their $P 311^{-/-}$coun- 
A

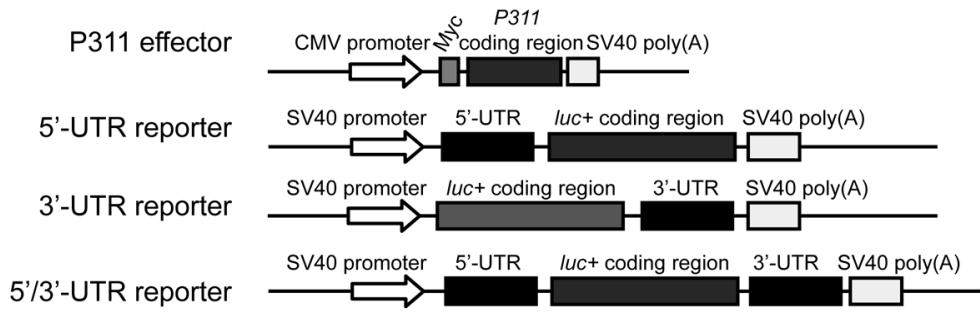

B

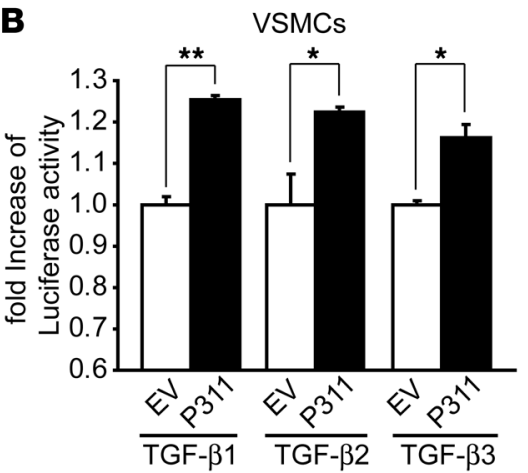

5'/3'-UTR 5'/3'-UTR 5'/3'-UTR
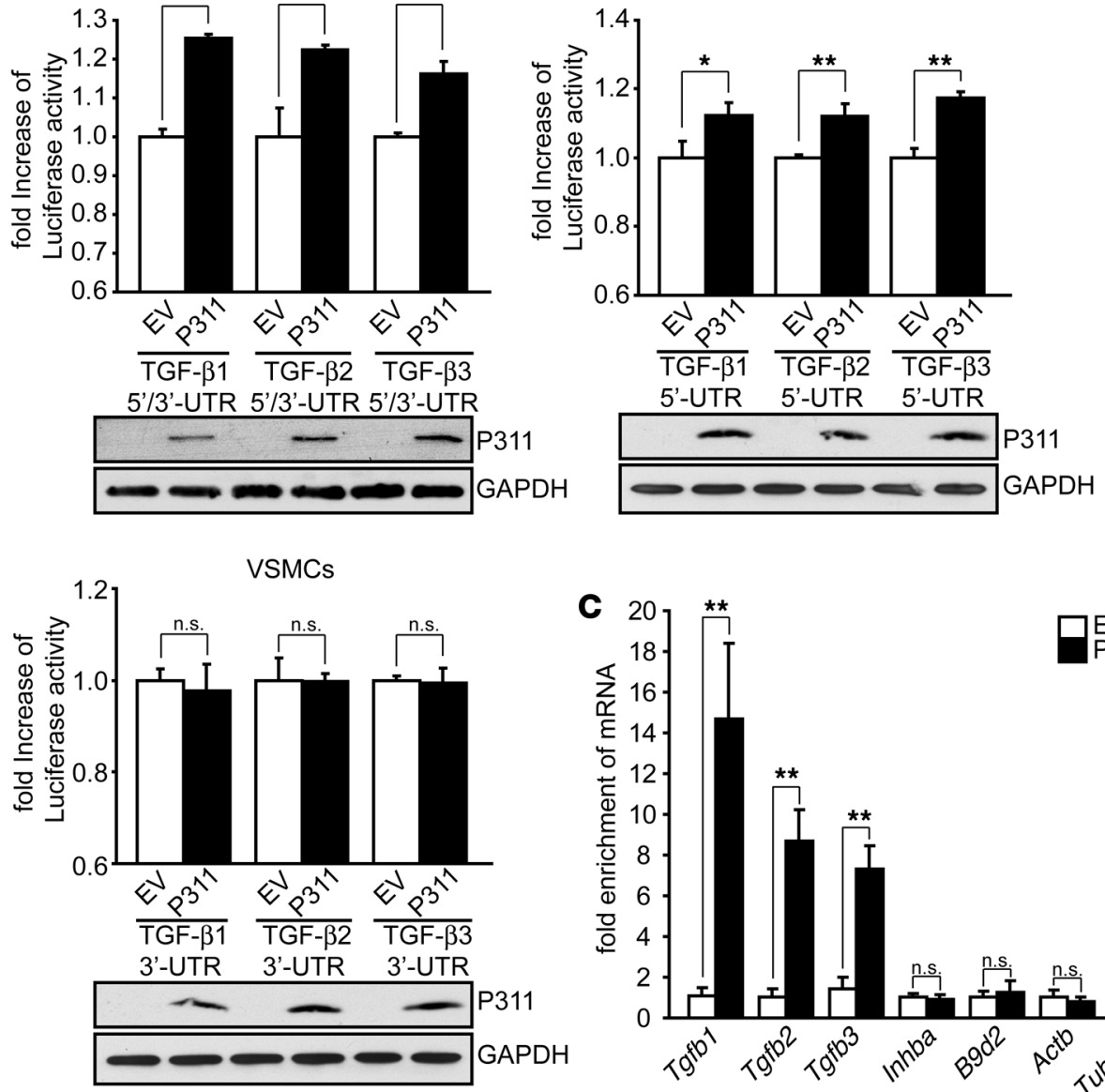

VSMCs

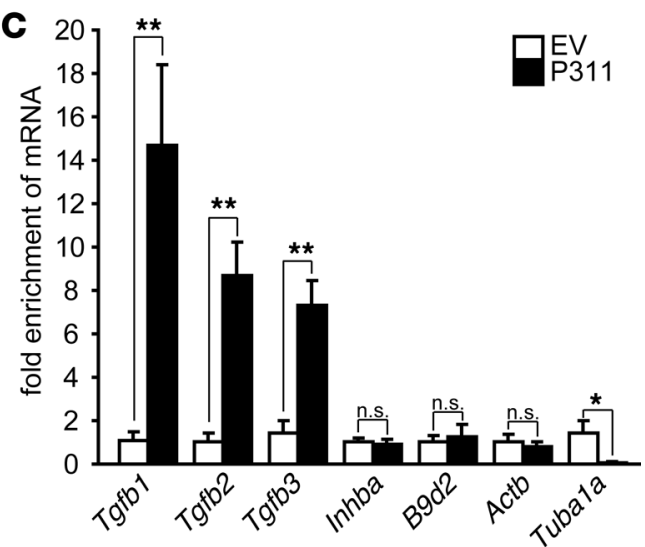

Figure 3

P311 upregulates translation of TGF- $\beta$ s through interaction with TGF- $\beta$ UTRs. (A) pGL3 UTR luciferase reporter constructs. (B) Luciferase reporter assay for TGF- $\beta$ 5'- and $3^{\prime}$-UTRs in P311-- mouse VSMCs transfected with P311 or empty vector. (C) P311-mRNA immunoprecipitation showing enrichment of 5'-UTR Tgfb1, Tgfb2, and Tgfb3 mRNAs as well as controls Inhba (TGF- $\beta$ superfamily member), B9d2 (TGF- $\beta$ neighboring gene on chromosome 7), Actb, and Tuba1a. Data represent mean \pm SD. ${ }^{*} P<0.05,{ }^{* *} P<0.01$, 1-way ANOVA. Unless otherwise specified, experiments were performed at least 3 times. terparts (Figure 2E). VSMCs cultures also showed increased Tgfb1, $T g f b 2$, and $T g f b 3 \mathrm{mRNA}$ levels, while protein levels were decreased (Supplemental Figure 5, A and B). Consistent with these findings, phosphorylation of the transcriptional coregulators Smad2 and Smad3 was also decreased (Figure $2 \mathrm{~F}$ ). Mice carrying an active TGF- $\beta$ reporter construct, $C A G A_{12} / G F P$, showed lower activity in $P 311^{-/-}$versus $P 311^{+/+}$animals (Figure $2 \mathrm{G}$ ). $P 311^{-/-}$VSMCs isolated from $C A G A_{12} / G F P$-transgenic mouse aortas also showed a loss of TGF- $\beta$ activity relative to WT controls (Supplemental Figure 5C).

P311 upregulates translation of TGF- $\beta$ s. The increase in TGF- $\beta$ mRNAs, combined with the decrease in TGF- $\beta$ isoform levels, suggested that $\mathrm{P} 311$ regulates TGF- $\beta$ translation, degradation, or both. Since we previously found that P311 binds to LAP (6), we first considered the possibility that P311 is involved in TGF- $\beta$ degradation through the engagement of its PEST domain. Ubiquitin immunoprecipitation assays showed no dif- ferences in ubiquitin-bound TGF- $\beta$ between aortas from $P 311^{-}-$ and WT mice (Supplemental Figure 6). Luciferase untranslated region (UTR) expression vectors, including the $5^{\prime}$ - and $3^{\prime}$-UTRs of TGF- $\beta 1$, TGF- $\beta 2$, or TGF- $\beta 3$ (Figure $3 \mathrm{~A}$ ), demonstrated increased translation in $P 311^{-/-}$-derived VSMCs transfected with P311 compared with empty vector control (Figure 3B). Further analyses demonstrated that the stimulatory effect of P311 on luciferase expression was confined to the 5'-UTR of the respective TGF- $\beta$ isoforms (Figure $3 \mathrm{~B}$ ). RNA immunoprecipitation revealed enrichment of TGF- $\beta 5^{\prime}$-UTR mRNAs in $P 311^{-/-}$-derived VSMCs transfected with P311 compared with sham-transfected VSMCs and other controls (Figure 3C).

Recombinant TGF- $\beta$ s restore $P 311^{-/-}$mouse blood pressure as well as vascular muscle tone and contractility. In rescue experiments, $P 311^{-/-}$ and WT mice were treated with a combination of TGF- $\beta 1$, TGF$\beta 2$, and TGF- $\beta 3$ (referred to herein as TGF- $\beta 1-3$ ), delivered 
A

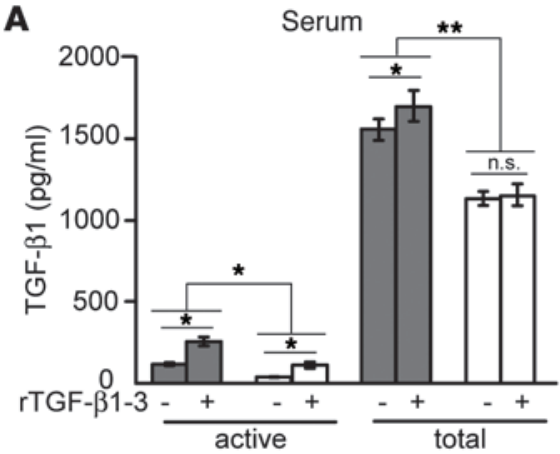

B
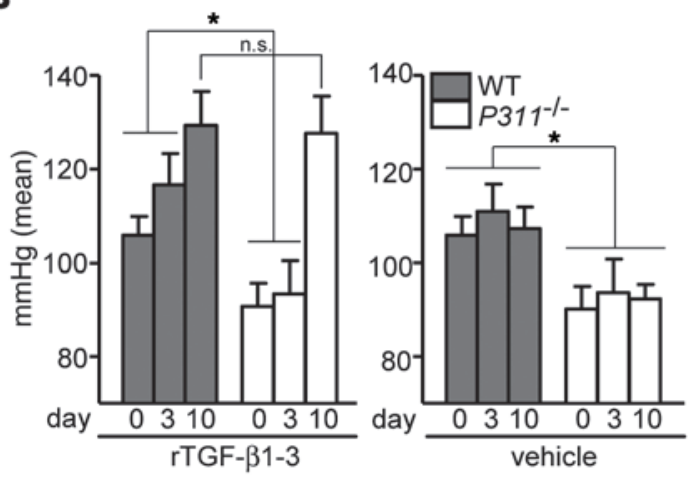
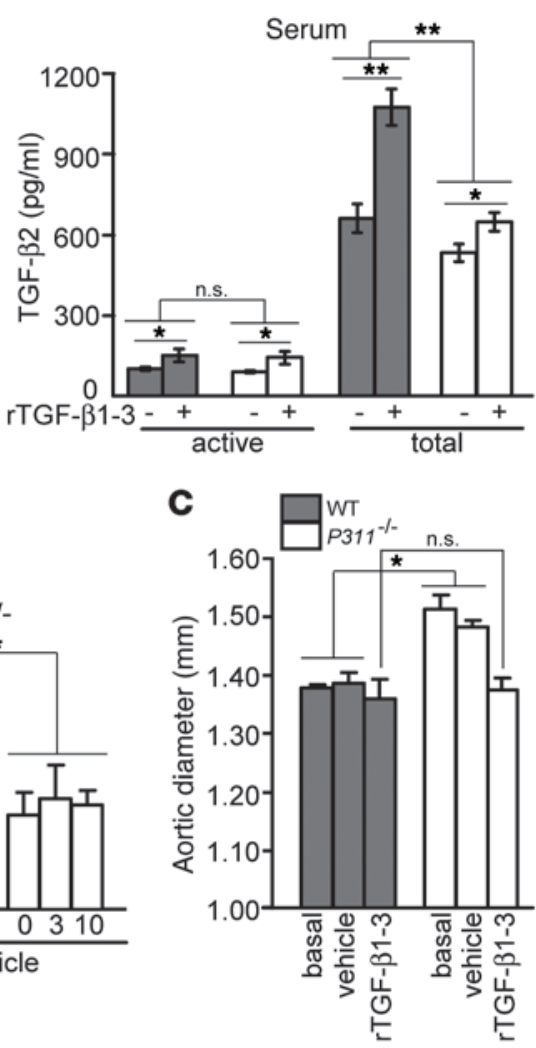

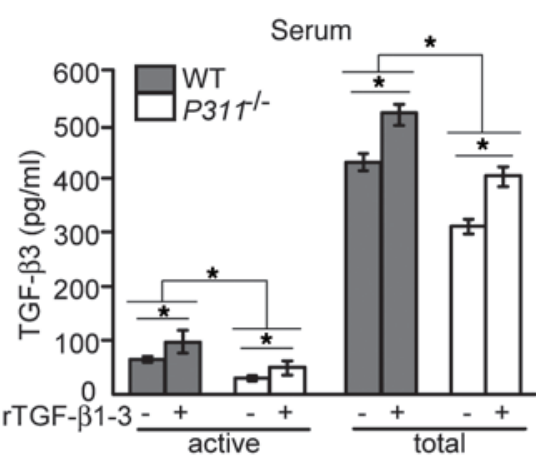

D

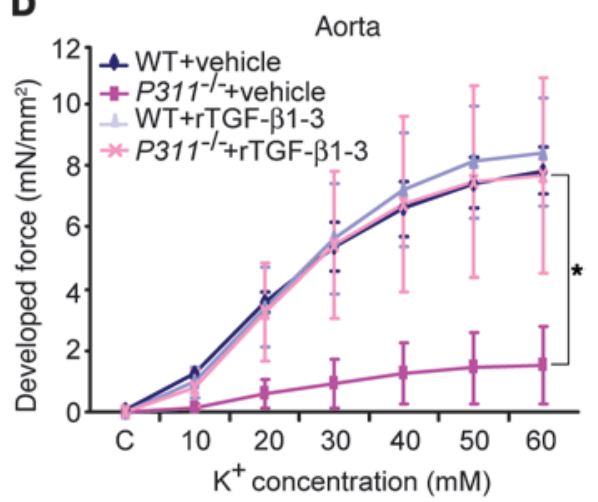

$\mathbf{F}$

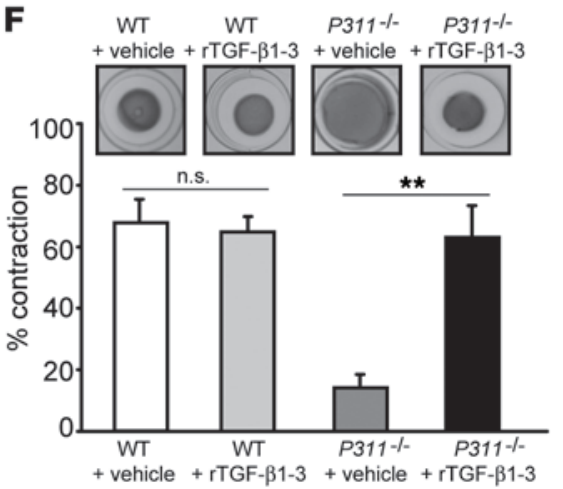

Figure 4

Administration of recombinant TGF- $\beta$ s restores blood pressure as well as vascular muscle tone, contractility, and RhoA activity to $P 311^{-1-}$ mice. (A) ELISA showing total and active TGF- $\beta$ s in blood serum of WT and P311-/ mice ( $n=4$ per group), treated or not with rTGF- $\beta 1-3$. (B) Plethysmographic blood pressure determination ( $n=5$ per group), with and without rTGF- $\beta 1-3$ treatment. (C) Echocardiographic aortic diameter in conscious mice ( $n=5$ per group) at basal levels and after treatment with rTGF- $\beta 1-3$ or vehicle. (D) Contractile response of mouse aortas ( $n=5$ per group) to increasing $\mathrm{K}^{+}$concentration, with and without rTGF- $\beta 1-3$ treatment. (E) RhoA activity assay showing total and active RhoA in mouse aortas ( $n=3$ per group), with and without rTGF- $\beta 1-3$ treatment. Relative density of total and active RhoA is also shown. (F) Collagen gel contraction by mouse aorta-derived VSMCs, with and without rTGF- $\beta 1-3$ treatment. Relative contraction is also shown, calculated as percent decrease in collagen gel diameter from the original diameter. Gel contraction data were collected from triplicate wells. Data represent mean \pm SD. ${ }^{*} P<0.05,{ }^{* *} P<0.01$, 1-way ANOVA.

intraperitoneally at a dosage sufficient to correct the decrease in plasma levels of active TGF- $\beta$ observed in $P 311^{-/-}$mice (Figure 4A). TGF- $\beta 1-3$ administration restored blood pressure as well as vascular tone, contractility, and RhoA activity in $P 311^{-/-}$mice (Figure 4, B-E). Over a period of 10 days, TGF- $\beta$ supplementation induced comparable hypertensive responses in $P 311^{-/-}$and WT mice, as determined by plethysmography (Figure 4B), despite TGF- $\beta 1-3$ in plasma reaching higher levels in WT mice (Figure 4A). Collagen gel contraction assays showed restoration of contractility in $\mathrm{P} 311^{-/-}$ VSMCs after TGF- $\beta 1-3$ treatment (Figure $4 \mathrm{~F}$ ). When administered individually, TGF- $\beta 1$ and TGF- $\beta 3$ exerted effects comparable to those observed with TGF- $\beta 1-3$ (albeit less pronounced in magnitude), whereas TGF- $\beta 2$ had no effect (Supplemental Figures 7-9).

$P 311$ overexpression increases the level and activity of pro-TGF- $\beta$ s and TGF- $\beta$ s and causes bypertension in mice. P311-transgenic $\left(P 311^{T G}\right)$ mice exhibited increased levels in all 3 pro-TGF- $\beta$ s in aortic 

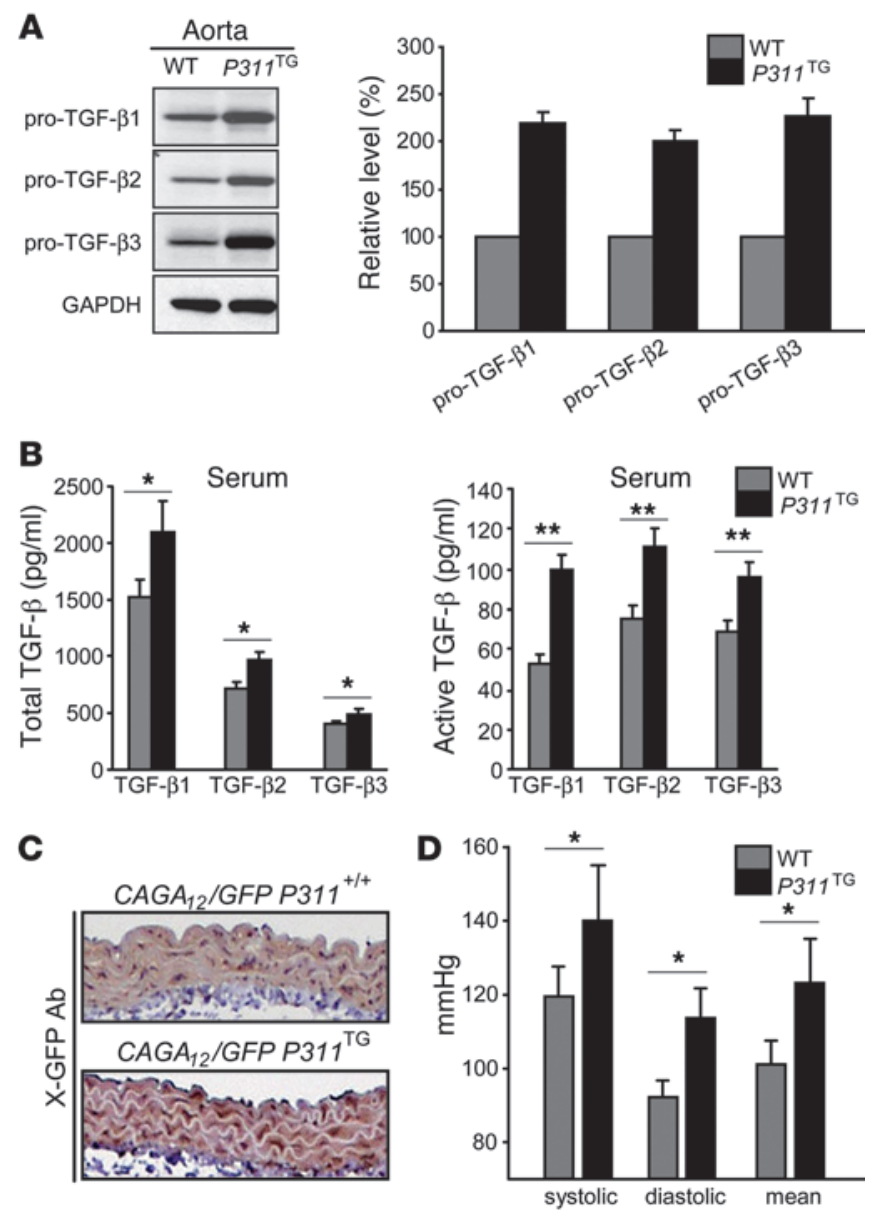

tissues, resulting in increased plasma levels of total and active TGF- $\beta 1$, TGF- $\beta 2$, and TGF- $\beta 3$ (Figure 5, A and B). Increased TGF- $\beta$ activity was also confirmed in $C A G A_{12} / G F P$ reporter mice (Figure 5C). Consistent with the increased TGF- $\beta$ expression levels and activity, $P 311^{T G}$ mice developed systolic and diastolic hypertension, as determined by plethysmography (Figure 5D).

P311 is overexpressed in buman bypertensive arteries. P311 levels were assessed in arterial tissue recovered from normotensive and hypertensive patients. Real-time PCR showed increased P311 mRNA levels in aortic tissues from hypertensive males relative to sex-matched normotensive controls (Figure 6A). In addition, IHC analyses demonstrated higher $\mathrm{P} 311$ protein levels in both arteries and arterioles from hypertensive males compared with normotensive controls (Figure 6B). Consistent with these findings, TGF- $\beta$ levels were increased in arteries from hypertensive patients compared with normotensive controls, and so were the nuclear levels of Smad2 and Smad3 (Figure 6, C and D), indicative of increased TGF- $\beta$ activity.

\section{Discussion}

P311 is a highly conserved, $8-\mathrm{kDa}$ intracellular protein abundantly expressed in the nervous system and in VSMCs and visceral smooth muscle cells with roles in myofibroblast transformation, cell migration, and tissue regeneration. Deletion of P311 in mice results in no overt phenotype (15). However, consistent with a functional role for P311 in the brain, these $P 311^{-/-}$mice display

\section{Figure 5}

Transgenic $P 311$ overexpression in mice increases level and activity of pro-TGF- $\beta$ s and TGF- $\beta$ s and causes hypertension. (A) Western blots showing pro-TGF- $\beta$ s in WT and $P 311^{T G}$ mouse aortas. Relative density of TGF- $\beta$ s in aortas is also shown ( $n=6$ per group). (B) ELISA showing levels of total and active TGF- $\beta$ s in blood serum. (C) GFP immunoreactivity (brown staining) in $C A G A_{12} / G F P$-transgenic $P 311^{+/+}$and $P 311^{T G}$ mouse aortas. Original magnification, $\times 10$. (D) Plethysmographic blood pressure determination ( $n=8$ per group). Experiments in which the number of animals is not specified were conducted 3 times. Data represent mean \pm SD. ${ }^{*} P<0.05,{ }^{* \star} P<0.01,1$-way ANOVA.

learning and memory defects $(15,16)$. Since P311 is also expressed at high levels in VSMCs, we explored its potential role within the systemic vasculature.

Western blot analysis and IHC confirmed the presence of P311 in mouse and human vascular muscle and its absence in the vasculature of $\mathrm{P} 311^{-/-}$mice. Furthermore, IHC indicated that P311 expression was higher in arteries than in veins. Gross examination and morphometry demonstrated normal blood vessel organization and histological architecture in $\mathrm{P} 311^{-/-}$mice; however, echocardiographic studies performed in conscious mice revealed an enlarged aortic diameter that disappeared under general anesthesia, a finding that suggests, among other things, a decrease in myogenic tone. Consistent with such a possibility, $P 311^{-/-}$animals displayed significant systemic hypotension. These changes were intrinsic to the vascular smooth muscle, rather than a result of P311 lacking in the nervous system, since aortas and resistance arteries isolated from $P 311^{-/-}$mice demonstrated hypocontractility in response to various vasoconstriction agonists. RhoA activity, a critical determinant of blood pressure and vascular muscle contractility (27), was also reduced in $\mathrm{P}_{311^{-/}}$aortas. Consistent with the fact that active RhoA promotes vascular muscle contraction by inhibiting myosin light chain phosphatase (MLCP; via ROCK-mediated phosphorylation of its regulatory subunit, MYPT1) (28), the phosphorylated fraction of MYPT1 was decreased in $P 311^{-/-}$mice. Finally, VSMCs isolated from $P 311^{-/-}$aortas were less efficient in contracting collagen gels than those derived from WT animals, while contraction improved after P311 transfection, confirming that the functional abnormality rested on the vascular muscle itself and that P311 directly regulated VSMC contractility.

We and others have reported that P311 modulates TGF- $\beta$ expression when transfected into NIH-3T3 fibroblasts $(1,5,6)$. Thus, we next determined the expression of TGF- $\beta 1$, TGF- $\beta 2$, and TGF- $\beta 3$ in $P 311^{-/-}$and WT aortas. Interestingly, while $T g f b 1, T g f b 2$, and $T g f b 3$ mRNA levels were upregulated in aortic tissues isolated from $P 311^{-/-}$mice, total and active protein levels of the 3 isoforms were severely decreased in VSMCs as well as in plasma samples of these mice. The reduced TGF- $\beta$ activity occurred at the level of pro-TGF- $\beta 1$, pro-TGF- $\beta 2$, and pro-TGF- $\beta 3$ expression, with accompanying decreases in the corresponding levels of LAP, which noncovalently associates with mature TGF- $\beta$. Consistent with these findings, downstream targets of TGF- $\beta$ signaling, (i.e., the phosphorylated transcriptional coregulators Smad2 and Smad3) were also decreased. Furthermore, $P 311^{-/-}$mice carrying an active TGF- $\beta$ reporter construct, $C A G A_{12} / G F P$, confirmed lower activity than their WT counterparts in whole aortas and in VSMC cultures. These results differed from our previous observations with NIH-3T3 cells, in which P311 transfection abrogated TGF- $\beta 1$ and TGF- $\beta 2$ expression without affecting TGF- $\beta 3$ expression (6). The 
A

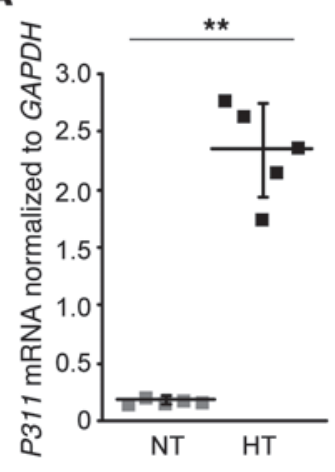

C

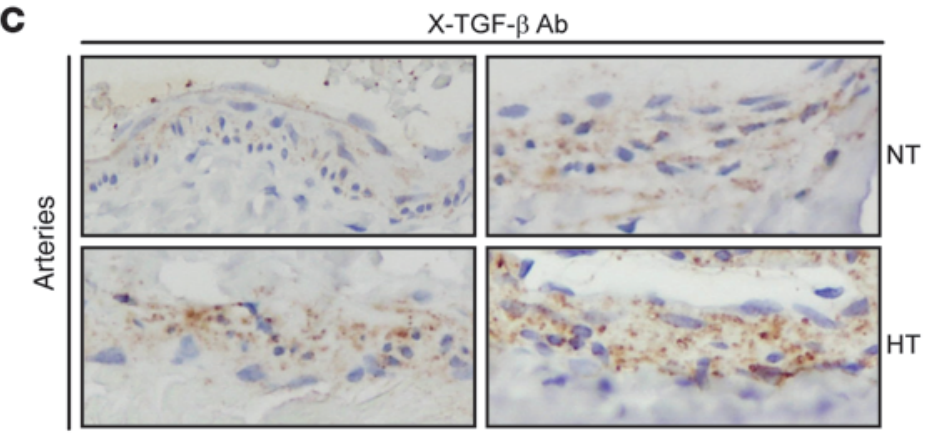

D

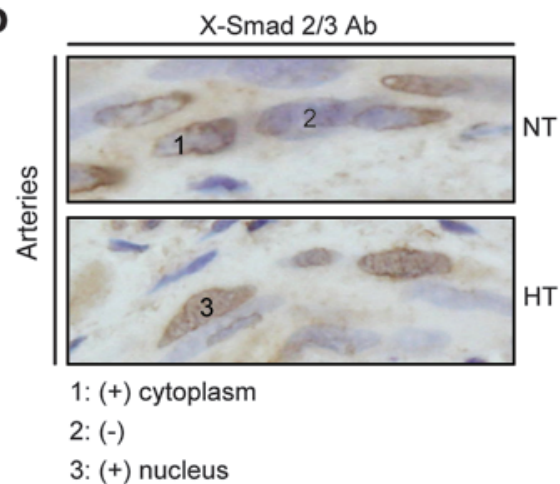

B

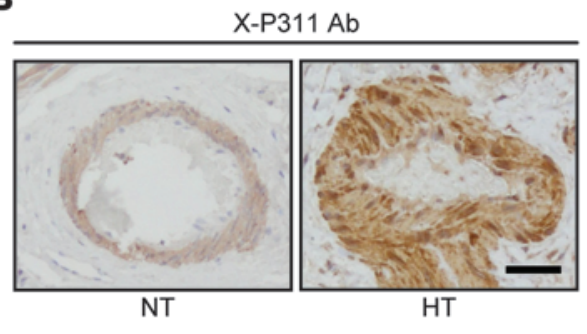

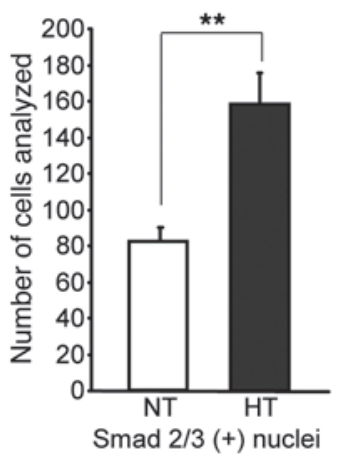

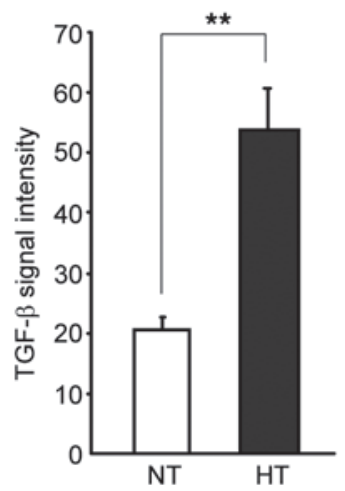

\section{Figure 6}

Human hypertensive arteries overexpress P311. (A) Real-time PCR showing mRNA levels of P311 in aortas from normotensive (NT) and hypertensive (HT) patients ( $n=5$ per group). (B) P311 immunoreactivity (brown staining) in hernia sac arteries from 18 normotensive and 21 hypertensive patients. Scale bar: $50 \mu \mathrm{m}$. Quantified P311 signal intensity is also shown. (C) TGF- $\beta$ immunoreactivity (brown staining) in hernia sac arteries from 18 normotensive and 21 hypertensive patients. Quantified TGF- $\beta$ signal intensity is also shown. Original magnification, $\times 25$. (D) Smad2/3 immunoreactivity (brown staining) in hernia sac arteries from normotensive and hypertensive patients. Original magnification, $\times 100$. The number of positive Smad2/3 nuclei is also shown. Data represent mean \pm SD. ${ }^{*} P<0.01,1$-way ANOVA.

observation that NIH-3T3 cells and VSMCs responded differently to P311 suggests that its effect is cell specific, a possibility further supported by a prior observation that P311 overexpression stimulates TGF- $\beta 1$ transcription in dermal fibroblast cultures (5). Our in vivo findings, however, were inconsistent with a role for P311 in TGF- $\beta$ transcription by VSMCs.

Remarkably, TGF- $\beta 1-3$ administration alone restored blood pressure, contractility, and RhoA activity in $P 311^{-/-}$mice. In a similar fashion, contractility was also restored in $P 311^{-/-}$VSMCs after treatment with the TGF- $\beta 1-3$ cocktail. When administered individually, TGF- $\beta 1$ and TGF- $\beta 3$ exerted effects comparable to those observed with TGF- $\beta$ 1-3 (albeit less pronounced), whereas
TGF- $\beta 2$ had no effect. While prior studies demonstrated a role for TGF- $\beta 1$ in blood pressure regulation (29-31), this represents the first instance in which the potential effect of TGF- $\beta 2$ and TGF- $\beta 3$ in blood pressure levels was assessed and the first demonstration that TGF- $\beta 3$ increased them.

To determine whether P311 can directly regulate TGF- $\beta$ activity and vascular tone in vivo, we generated transgenic mice overexpressing P311. As predicted, P311 transgenic mice exhibited an increase in all 3 pro-TGF- $\beta$ levels in aortic tissues, with increased TGF- $\beta$ activity - as indicated by the $C A G A_{12} / G F P$ reporter mice resulting in increased plasma levels of total and active TGF- $\beta 1$, TGF- $\beta 2$, and TGF- $\beta 3$, as recorded for human hypertension and 
TGF- $\beta 1$ (32-34). Furthermore, the P311 transgenic mice developed hypertension, which indicates not only that P311 is needed to prevent hypotension, but that its increase is sufficient to cause high blood pressure.

The increase in TGF- $\beta$ mRNAs in $P 311^{-/-}$mice, combined with the decrease in TGF- $\beta$ isoforms observed, suggests that P311 regulates TGF- $\beta$ at the posttranscriptional level, acting at translation, degradation, or both. Ubiquitin immunoprecipitation assays ruled out differences in degradation. However, when luciferase expression vectors were constructed that included the $5^{\prime}$ and $3^{\prime}$-UTRs of TGF- $\beta 1$, TGF- $\beta 2$ or TGF- $\beta 3$, the luciferase protein was expressed at lower levels in $\mathrm{P}_{111^{-/}}$versus WT cells, which indicates that P311 regulates translation of TGF- $\beta$ s. Further analyses demonstrated that the stimulatory effect of P311 on luciferase expression was confined to the 5 '-UTR of the respective TGF- $\beta$ isoforms. In addition, RNA immunoprecipitation revealed enrichment of the TGF- $\beta$ 5'-UTR mRNAs in VSMCs isolated from P311-transfected P311 ${ }^{-/-}$mice compared with sham-transfected controls, consistent with a role for P311 in translation of TGF- $\beta$ s. Since P311 has no RNA-binding motifs, the P311-mRNA interaction is likely to be indirect through one or more yet-uncharacterized proteins. Hence, P311 controls TGF- $\beta$ levels and/or activity by acting as the first known regulator of its translational activity.

As P311 had not been previously linked to blood vessel homeostasis, we finally considered the possibility that the protein plays a role in human hypertension. We assessed P311 levels in arterial tissue recovered from normotensive and hypertensive patients. Indeed, increased $P 311$ mRNA levels were detected in aortic tissues from hypertensive males relative to sex-matched normotensive controls. In addition, IHC analyses confirmed higher P311 protein levels in both arteries and arterioles from hypertensive versus normotensive tissue. Although our studies showed that increased P311 level per se led to hypertension, it is possible that the high P311 expression detected in arteries of hypertensive patients is, in part, the result of increased mechanical stress, since in previous studies we found that mechanical tension induces P311 in embryonic mesenchymal cells (1). Taken together, these data support the conclusion that P311 plays a heretofore unrealized role in modulating hypertensive responses in humans.

TGF- $\beta$ is known to act as a critical effector of blood pressure regulation (29-31). To date, however, the pathophysiologic control of TGF- $\beta$-dependent vascular tone has largely been confined to angiotensin II, whose action is in great part mediated by TGF- $\beta$ (35-38) and TGF- $\beta 1$ polymorphisms (39-42). Herein, we identified P311 as a previously unrecognized major regulator of the TGF- $\beta$-vascular tone axis. In the absence of P311, total and active levels of TGF- $\beta 1$, TGF- $\beta 2$, and TGF- $\beta 3$ decreased in vascular muscle and plasma, in tandem with decreased RhoA activity and increased MLCP activity, resulting in low vascular contractility, tone, and hypotension. These abnormalities were intrinsic to the vascular muscle, as opposed to resulting from lack of P311 in the nervous system. In contrast, mice overexpressing P311 featured increased production of TGF- $\beta$ s in the vascular musculature and increased circulating levels of TGF- $\beta 1$, TGF- $\beta 2$, and TGF- $\beta 3$ as well as TGF- $\beta$ activity in vivo, while displaying a hypertensive phenotype. These data, combined with the observed linkage of increased mRNA and protein levels of P311 in hypertensive humans, served to identify P311 as a new and potentially important effector of blood pressure regulation.

\section{Methods}

Mice. Generation of $P 311^{-/-}$mice (C57BL/6 mice with deletion of the entire P311 coding region on both alleles) was described previously (15). For in vivo determination of TGF- $\beta$ activity, transgenic mice were generated by crossing $C A G A_{12} / G F P$ animals (carrying a TGF- $\beta$-responsive promoter element $C A G A_{12}$ upstream of GFP; provided by H.C. Dietz, Johns Hopkins University School of Medicine, Baltimore, Maryland, USA) with WT $\left(P 311^{+/+}\right)$or $P 311^{-/-}$animals. TGF- $\beta$ activation in reporter mouse tissues was histologically visualized by IHC with an Ab against GFP (Abcam). For P311 overexpression, transgenic mice were created by using PBROAD3 vector (InvivoGen) under the control of ROSA26 promoter. The P311 ${ }^{T G}$ line was selected by real-time PCR of P311 and used for further breeding. 4-month-old males were used in this study, and age-matched WT C57BL/ 6 mice (Charles River Laboratories) were used as controls. Animals were housed at the University of Chicago animal facility $\left(20^{\circ} \mathrm{C} \sim 25^{\circ} \mathrm{C}\right.$ and 12-hour light cycle) and supplied with rodent diet no. 2918 (18\% protein, $6 \%$ fat and moderate phytoestrogen; Harlan Laboratories).

Blood vessel collection from mice and from human tissues. Aortas and first-branch mesenteric arteries were dissected from the mice, and the attached fat and soft tissues were trimmed under a microdissecting microscope. The dissected blood vessels were immediately used for experiments or frozen at $-80^{\circ} \mathrm{C}$ until use. For real-time PCR, samples of abdominal aorta, right below the diaphragm, from 5 normotensive male patients and 5 hypertensive male patients (age $60 \pm 3$ years) were collected from autopsies within 4 hours postmortem. For IHC, paraffin blocks from surgically removed, uncomplicated hernia sacs from 18 normotensive male patients and 21 hypertensive male patients (age $60 \pm 3$ years) were selected from the Department of Pathology archival material. In all cases, the history of hypertension was $5 \pm 2$ years, blood pressure values at the time of diagnoses were $100 \pm 5$ over $150 \pm 5$, and all had a record of poor treatment compliance. None of the patients had past or present history of additional illnesses.

Blood pressure determination by telemetry and plethysmography. TA11PA-C10 telemetry devices (Data Sciences International) were implanted subcutaneously along the flanks of 8 P311//- mice and 8 WT controls for chronic acquisition of blood pressure parameters and heart rate. The devices' catheters were placed with the tip at least $2 \mathrm{~mm}$ into the aortic arch. Data from WT and $P 311^{-/-}$mice were collected for a 1-week period and analyzed using Dataquest A.R.T. software (supplied by Data Sciences International).

Plethysmographic blood pressure was recorded using an 8-channel CODA noninvasive blood pressure acquisition system (Kent Scientific) following the manufacturer's protocol. Mice were placed in a clear acrylic restrainer with a built-in nose cone for at least 30 minutes prior to obtaining pressure measurements. Systolic, diastolic, and mean blood pressure as well as heart rate were recorded. Blood pressures were monitored on days 0 , 3,6 , and 10 of TGF- $\beta$ treatment studies.

Echocardiography. Transthoracic echocardiography was performed in awake and anesthetized mice using a Doppler system (Acuson c256) equipped with a $15-\mathrm{MHz}$ linear transducer (15L-8) (43). The heart was first imaged in the $2 \mathrm{D}$ mode in the parasternal long-axis view, for measurement of wall thickness and chamber dimensions as well as aortic dimension. LV cross-sectional area at end-diastole and -systole were measured on a $2 \mathrm{D}$ short-axis view of the papillary muscles. The following parameters were also obtained: (a) LV chamber dimensions; (b) LV wall thickness; (c) LV mass (LVM); (d) LV ejection fraction (LVEF); (e) shortening fraction; (f) cardiac output; and (g) aortic dimensions.

Administration of recombinant TGF- $\beta$ s. Mice were intraperitoneally injected with recombinant ( $r$ ) human TGF- $\beta 1$, rTGF- $\beta 2$, rTGF- $\beta 3$, or rTGF- $\beta 1-3$ (R\&D Systems). Injections were given to mice once daily for 10 days at a dose of $250 \mathrm{ng}$ (rTGF- $\beta 1$, rTGF- $\beta 2$, and rTGF- $\beta 3$ ) or 
100 ng of each (rTGF- $\beta 1-3$ ). Before and after rTGF- $\beta$ treatments, blood pressure was monitored, and echocardiography was performed (only for combined rTGF- $\beta 1$-3 treatment). After 10 days of treatment, aortas were isolated for myography studies, along with Western blot analysis or ELISA (see below).

Wire myography. Thoracic aortas and mesenteric resistance arteries were cut into rings approximately $2 \mathrm{~mm}$ in length, and contractility was measured with a DMT 610M multi-myograph system (DMT-USA Inc.). Optimal tension was initially applied, and tissues were allowed to equilibrate for 1 hour in $5 \mathrm{ml}$ physiological salt solution (PSS; containing $118.99 \mathrm{mM}$ $\mathrm{NaCl}, 25 \mathrm{mM} \mathrm{NaHCO}_{3}, 4.69 \mathrm{mM} \mathrm{KCl}, 1.18 \mathrm{mM} \mathrm{KH}_{2} \mathrm{PO}_{4}, 1.17 \mathrm{mM} \mathrm{MgSO}_{4}$, $2.5 \mathrm{mM} \mathrm{CaCl}_{2}, 0.03 \mathrm{mM}$ EDTA, and $5.5 \mathrm{mM}$ glucose) at $37^{\circ} \mathrm{C}$, gently pumped with a gas mixture of $95 \% \mathrm{O}_{2}$ and $5 \% \mathrm{CO}_{2}$. For TGF- $\beta$ receptor inhibitor treatment, PSS containing $100 \mu \mathrm{M}$ LY364947 (Sigma-Aldrich) was used. Aortic and arterial contractions were determined after sequential addition of $\mathrm{KCl}$, vasoconstrictors (norepinephrine, phenylephrine, epinephrine, and angiotensin II; Sigma-Aldrich), or vasodilator (hydralazine; Sigma-Aldrich) to PSS buffer.

Pressure myography. Mesenteric resistance arteries (100-150 $\mu \mathrm{m}$ in diameter) were dissected in PSS buffer and mounted on a DMT 110P pressure myograph system (DMT-USA Inc.). Myogenic tone was assessed by subjecting the arteries to a series of pressure steps $(10-125 \mathrm{mmHg})$, and lumen diameters were recorded. Active and passive diameters were determined in PSS buffer (containing $2.5 \mathrm{mM} \mathrm{CaC1}_{2}$ ) or $\mathrm{Ca}^{2+}$-free PSS buffer (containing $2 \mathrm{mM}$ EGTA instead), respectively. Myogenic tone was calculated as percent constriction relative to the passive lumen diameter at each respective transmural pressure: ([diameter passive $_{-}-$diameter $\left._{\text {active }}\right] /$ diameter $\left._{\text {passive }}\right) \times 100$. An intermediate pressure $(75 \mathrm{mmHg})$ was used to determine the response of arteries to $\mathrm{K}^{+}$.

RhoA activity assay. GTP-bound (i.e., active) RhoA was isolated from aortas using a commercial kit (Millipore). Aortas from WT and $\mathrm{P} 311^{-/-}$mice were lysed with Rho-binding lysis buffer (50 mM Tris, $\mathrm{pH} 7.2,1 \%$ Triton $\mathrm{X}-100,0.5 \%$ sodium deoxycholate, $0.1 \% \mathrm{SDS}, 500 \mathrm{mM} \mathrm{NaCl}, 10 \mathrm{mM} \mathrm{MgCl} 2$ with $10 \mu \mathrm{g} / \mathrm{ml}$ leupeptin, $10 \mu \mathrm{g} / \mathrm{ml}$ aprotinin, and $1 \mathrm{mM} \mathrm{PMSF}$ ). Lysates were clarified by centrifugation, and active RhoA was precipitated with agarose beads conjugated with $20 \mu \mathrm{g}$ of a GST-tagged fusion protein corresponding to residues 7 89 of mouse rhotekin Rho-binding domain. Precipitates were subjected to immunoblotting with RhoA Ab supplied in the kit. Aorta lysates incubated with $100 \mu \mathrm{M}$ GTP $\gamma$ S and $1 \mathrm{mM}$ GDP were used as positive and negative controls, respectively.

Morphometry. Dissected aorta and mesenteric arteries from WT and $P 311^{-/-}$mice were formalin fixed and paraffin embedded. 5- $\mu \mathrm{m}$ aorta sections were stained with DAPI nuclear dye $(5 \mu \mathrm{g} / \mathrm{ml}$ in water) for 10 minutes and observed under a Zeiss Axioplan microscope equipped with epifluorescence optics. For each field, 2 images were acquired by a Leica DC500 digital camera to visualize elastic lamina (autofluorescence observed in the fluorescein channel) and nuclei (observed using a UV filter set). The images were then overlapped using Leica IM 1000 Image Manager software. The length of the innermost elastic lamina (IEL) and the number of nuclei comprised between two elastic laminas in the aorta, and between internal and external elastic lamina in the mesenteric arteries were determined using Metamorph software (version 7.5; Molecular Devices).

TGF- $\beta$ ELISA. ELISAs were performed using Emax Immuno assay system (Promega) with modified protocols on fresh aortic tissues and serum. TGF- $\beta 1 \mathrm{mAb}$ (supplied in the kit), TGF- $\beta 2 \mathrm{mAb}$ (MAB612; R\&D Systems), and TGF- $\beta 3 \mathrm{mAb}$ (MAB643; R\&D Systems) were coated on a 96 -well plate and incubated overnight at $4^{\circ} \mathrm{C}$. After blocking, TGF- $\beta$ protein standards and acidified or nonacidified serum samples (to show total or active TGF- $\beta$ s, respectively) were allowed to bind at room temperature for 1.5 hours. Secondary Abs - TGF- $\beta 1$ polyclonal Ab (pAb) (supplied in the kit), TGF- $\beta 2$ pAb (BAF302; R\&D Systems), and TGF- $\beta 3$ pAb (BAF243; R\&D Systems) - were added to complete the sandwich, followed by the chromogenic substrate 3,3',5,5'-tetramethyl benzidine (TMB), stop solution $(1 \mathrm{~N} \mathrm{HCl})$, and recording of absorbance at $450 \mathrm{~nm}$.

IHC. IHC was performed at the University of Chicago Pathology Core Facility. The immunoperoxidase procedure was applied to formalin-fixed, paraffin-embedded aortas from WT and $P 311^{-/-}$mice and formalin-fixed, paraffin-embedded human tissues. 5 - $\mu \mathrm{m}$ tissue sections were incubated with anti-mouse P311 Ab (1:50 dilution; ref. 44), anti-human P311 Ab (1:50 dilution; ref. 45), anti-TGF- $\beta 1-3 \mathrm{Ab}$ (1:20 dilution; MAB1835; R\&D Systems) or anti-Smad2/3 Ab (1:50 dilution; sc-6033; Santa Cruz) after antigen unmasking by boiling in fresh citrate buffer, and reactions were developed with Vectastain ABC kit (Vector Laboratories). Intensity quantifications were performed in human artery muscular layer at 6 equidistant points. IHC figures were converted to 8-bit images, and densitometry was conducted using Image J (version 1.41x; NIH).

VSMC culture. Isolated aortas were denuded of adventitial layer by microdissection and of endothelial cells by passing through a sterile pipette tip and kept in Fungizone solution (Invitrogen) for $2 \sim 3 \mathrm{~min}$. The aortas were then cut into small pieces and incubated in $100 \mu \mathrm{l}$ of collagenase II enzyme solution $(1.5 \mathrm{mg} / \mathrm{ml})$ at $37^{\circ} \mathrm{C}$ for 5 hours. The VSMCs were then released from the digested tissues by pipetting up and down through a tip. The released cells were washed three times in PBS, resuspended in culture medium DMEM with 10\% FBS and seeded onto plates. VSMCs were used at passage 1.

RNA isolation and real-time PCR. RNA isolation and cDNA synthesis were done with aortic tissues and cultured aortic VSMCs using TRIzOL (Invitrogen) and iScript cDNA synthesis kit (Bio-Rad). Real-time PCR for mouse cDNA was conducted using iQ SYBR Green Supermix (Bio-Rad) and the following primers: Tgfb1 sense, $5^{\prime}$-TGAGTGGCTGTCTTTTGACG-3'; Tgfb1 antisense, 5'-TTCTCTGTGGAGCTGAAGCA-3'; Tgfb2 sense, 5'-GTGACATGGACAGTGGATGC-3'; Tgfb2 antisense, 5'-GCGGACGATTCTGAAGTAGG-3'; Tgf $b 3$ sense, $5^{\prime}$-TGGAGTCATGGCTGTAACT-3'; Tgfb3 antisense, 5'-CACTCACACTGGCAAGTAGT-3'; Gapdb sense, 5'-ATCACCATCTTCCAGGAGCGA-3'; Gapdh antisense, 5'-GCCAGTGAGCTTCCCGTTCA-3'. For detection of P311 mRNA from human aortas, the following primers were used: sense, $5^{\prime}$-TCCAAACAAGGACATGGAGGG-3'; antisense, 5'-AGGTAACTGATTCTTGGGGAG-3'.

$P 311$ transfection and reporter assay. For transient transfections, VSMCs at approximately $70 \%$ confluence were transfected with the P311 expression construct PCMV-Myc-P311 (Clontech) using Lipofectamine 2000 reagent in Opti-MEM (Invitrogen). At 24 hours after transfection, cells were trypsinized and used for gel contraction studies (see below). For reporter assay, TGF- $\beta 1-35^{\prime}$ - and $3^{\prime}$-UTR regions were cloned into pGL3-promoter firefly luciferase vector (Promega) to generate reporter constructs. $P 311^{-/-}$mouse VSMCs were plated on 6-well plates and transfected with the P311 expression vector, the reporter constructs, and renilla luciferase internal control vector pRL-SV40. 48 hours after cotransfection, the Dual-Luciferase Reporter Assay System (Promega) was used to determine the ratio of firefly/renilla luciferase activity, as indicated by the manufacturer.

RNA immunoprecipitation. 48 hours after transfection with the P311 expression construct PCMV-Myc-P311 or empty vector, cells were lysed in lysis buffer (25 mM Tris, $150 \mathrm{mM} \mathrm{NaCl}, 1 \mathrm{mM}$ EDTA, 1\% NP-40, 5\% glycerol, pH 7.4) supplied with Halt Protease Inhibitor Cocktail (Thermo Scientific). Cell lysates were subject to immunoprecipitation using anti-c-Myc agarose (A7470; Sigma-Aldrich). Agarose beads were washed 3 times in lysis buffer and resuspended in TRIzOL for RNA isolation. Coimmunoprecipitated RNAs were detected by real-time PCR using primers specific to Tgfb1 (sense, 5'-GCTCCCCTATTTAAGAACACCC-3'; 
antisense, 5'-TTGAGGTTGAGGGAGAAAGC-3'), Tgfb2 (sense, 5'-AGTGGGAGAGAAAGAGAGAAGG-3'; antisense, 5'-GCGACCCTAAAATAGACCTCTG-3'), Tgfb3 (sense, 5'-AAGAGAAGCAAGGGACAGAAG-3'; antisense, 5'-GCTGGGATGAGGGATTATGTAC-3'), Inbba (sense, 5'-TGACAAAACAGAAGGGACCC-3'; antisense, 5'-CAGCAAAAGTCGTGTGGTTG-3'), B9d2 (sense, 5'-ACAGTGCACCTTGGTATCG-3'; antisense, 5' -ACAGTCTCCAGAGTCCACG-3'), Actb (sense, 5'-CTGTATTCCCCTCCATCGTG-3'; antisense, 5'-GCCTCGTCACCCACATAG-3'), and Tuba1a (sense, 5'-GCGAAGCAGCAACCATG-3'; antisense, $5^{\prime}$-TCTTGTCACTTGGCATCTGG-3').

Gel-contraction studies. Gel-contraction studies were conducted using $5 \mathrm{ml}$ of rat tail collagen I solution $(2 \mathrm{mg} / \mathrm{ml}$ in $0.1 \%$ acetic acid) mixed with $1 \mathrm{ml}$ of $10 \times$ DMEM and $1 \mathrm{ml}$ of $0.1 \mathrm{~N} \mathrm{NaOH}$ to neutralize the $\mathrm{pH}$ before adding $3 \mathrm{ml}$ of trypsinized VSMCs (WT, P311 $1^{-1}$, and P311 expression vector-transfected $P 311^{-1-} ; 3 \times 10^{5}$ cells $/ \mathrm{ml}$ ) in culture medium. The mixed collagen gel solution was casted in $60-\mathrm{mm}$ culture plastic dishes ( $4 \mathrm{ml} /$ dish). After incubation at $37^{\circ} \mathrm{C}$ for 30 minutes, polymerized gels were detached and covered with $4 \mathrm{ml}$ DMEM with $10 \%$ FBS. Lattices were photographed after 7 days, and magnitudes of gel contraction were calculated. For treatment purposes, the polymerized gels were incubated with regular media containing rTGF- $\beta 1$, rTGF- $\beta 2$, rTGF- $\beta 3$, or rTGF- $\beta 1-3$ at a concentration of $10 \mathrm{ng} / \mathrm{ml}$.

Western blotting analysis. Aorta lysates and cultured aortic VSMC lysates (20 $\mu \mathrm{g}$ total protein) were resolved on SDS-PAGE gels and transferred onto nitrocellulose membranes (BioRad) for immunoblotting analysis. Abs against P311 (44, 45), TGF- $\beta$ s, LAP-1 (R\&D Systems), c-Myc (Sigma-Aldrich), MYPT1 (Cell Signaling Technology), phospho-MYPT1 (T696; Santa Cruz), and GAPDH (Santa Cruz) were used to detect target proteins. An ECL Plus Western blotting detection system (GE Healthcare) was used for detecting the chemiluminescence signal.
Statistics. All experiments were repeated at least 3 times, and data are shown as mean \pm SD. Differences between 2 groups and treatments were determined by 1-way ANOVA or by 2-tailed Student's $t$ test. A $P$ value of 0.05 or less was considered statistically significant.

Study approval. All animal procedures performed herein were approved by the University of Chicago IACUC in accordance with NIH guidelines. All protocols for human tissues were approved by the University of Chicago IRB according to NIH guidelines. All human tissues were obtained from the Human Tissue Resource Center at the University of Chicago (and therefore have deidentifiers); patient informed consent was not required.

\section{Acknowledgments}

We thank Harry C. Dietz for providing $C A G A_{12} / G F P$ transgenic mice and Yee Wong for excellent technical assistance in the performance of pressure myograph studies. This work was supported by NHLBI grants HL-48730, HL-77514, and HL-78752 to L. Schuger. K.R. Badri is an American Lung Association Interstitial Lung Disease Scholar (Dalsemer Research Award; DA-196629-N).

Received for publication March 14, 2013, and accepted in revised form July 18, 2013.

Address correspondence to: Lucia Schuger, Department of Pathology, The University of Chicago, 5841 S. Maryland Avenue, Chicago, Illinois 60637, USA. Phone: 773.702.4784; Fax: 773.795.6357; E-mail: 1schuger@bsd.uchicago.edu.

Kameswara Rao Badri's present address is: Office of Sponsored Research Administration, Savannah State University, Savannah, Georgia, USA.
1. Pan D, Zhe X, Jakkaraju S, Taylor GA, Schuger L. P31 1 induces a TGF- $\beta 1$-independent, nonfibrogenic myofibroblast phenotype. J Clin Invest. 2002;110(9):1349-1358.

2. Mariani L, et al. Identification and validation of P311 as a glioblastoma invasion gene using laser capture microdissection. Cancer Res. 2001;61(10):4190-4196.

3. Fujitani M, et al. P311 accelerates nerve regeneration of the axotomized facial nerve. J Neurochem. 2004;91(3):737-744.

4. Zhao L, et al. Identification of P311 as a potential gene regulating alveolar generation. Am J Respir Cell Mol Biol. 2006;35(1):48-54.

5. Tan J, et al. Investigating the role of P311 in the hypertrophic scar. PLoS One. 2010;5(4):e9995.

6. Paliwal S, Shi J, Dhru U, Zhou Y, Schuger L. P311 binds to the latency associated protein and downregulates the expression of TGF- $\beta 1$ and TGF- $\beta 2$. Biochem Biophys Res Commun. 2004;315(4):1104-1109.

7. Varshavsky A. The ubiquitin system. Trends Biochem Sci. 1997;22(10):383-387.

8. Stoven $\mathrm{S}$, et al. Caspase-mediated processing of the Drosophila NF-kappaB factor Relish. Proc Natl Acad Sci US A. 2003;100(10):5991-5996.

9. Alvarez M, Altafaj X, Aranda S, de la Luna S. DYRK1A autophosphorylation on serine residue 520 modulates its kinase activity via 14-3-3 binding. Mol Biol Cell. 2007;18(4):1167-1178.

10. Antonsson A, Payne E, Hengst K, McMillan NA. The human papillomavirus type $16 \mathrm{E} 7$ protein binds human interferon regulatory factor-9 via a novel PEST domain required for transformation. J Interferon Cytokine Res. 2006;26(7):455-461.

11. Bies J, Markus J, Wolff L. Covalent attachment of the SUMO-1 protein to the negative regulatory domain of the c-Myb transcription factor modifies its stability and transactivation capacity. J Biol
Chem. 2002;277(11):8999-9009.

12. Fisher RC, et al. Normal myeloid development requires both the glutamine-rich transactivation domain and the PEST region of transcription factor PU.1 but not the potent acidic transactivation domain. Mol Cell Biol. 1998;18(7):4347-4357.

13. Ghose R, Shekhtman A, Goger MJ, Ji H, Cowburn D. A novel, specific interaction involving the Csk SH3 domain and its natural ligand. Nat Struct Biol. 2001;8(11):998-1004.

14. Huang W, Horvath E, Eklund EA. PU.1, interferon regulatory factor (IRF) 2 , and the interferon consensus sequence-binding protein (ICSBP/IRF8) cooperate to activate NF1 transcription in differentiating myeloid cells. J Biol Chem. 2007;282(9):6629-6643.

15. Taylor GA, et al. Behavioral characterization of P311 knockout mice. Genes Brain Behav. 2008; 7(7):786-795.

16. Sun YG, et al. Involvement of P311 in the affective, but not in the sensory component of pain. Mol Pain. 2008; $4: 23$.

17. Massagué J. How cells read TGF- $\beta$ signals. Nat Rev Mol Cell Biol. 2000;1(3):169-178.

18. Kitisin K, et al. Tgf- $\beta$ signaling in development. Sci STKE. 2007;2007(399):cm1.

19. MassaguéJ. TGF- $\beta$ in cancer. Cell. 2008;134(2):215-230.

20. Massagué J, Chen YG. Controlling TGF- $\beta$ signaling. Genes Dev. 2000;14(6):627-644.

21. Annes JP, Munger JS, Rifkin DB. Making sense of latent TGF- $\beta$ activation. J Cell Sci. 2003; 116(pt 2):217-224.

22. Derynck R, Zhang YE. Smad-dependent and Smadindependent pathways in TGF- $\beta$ family signaling. Nature. 2003;425(6958):577-584.

23. Massagué J, Seoane J, Wotton D. Smad transcription factors. Genes Dev. 2005;19(23):2783-2810.

24. Bierie B, Moses HL. TGF- $\beta$ and cancer. Cytokine Growth Factor Rev. 2006;17(1-2):29-40.
25. Dennler S, et al. Direct binding of Smad3 and Smad 4 to critical TGF $\beta$-inducible elements in the promoter of human plasminogen activator inhibitor-type 1 gene. EMBO J. 1998;17(11):3091-3100.

26. Kusanagi K, Kawabata M, Mishima HK, Miyazono K. Alpha-helix 2 in the amino-terminal mad homology 1 domain is responsible for specific DNA binding of Smad3. J Biol Chem. 2001;276(30):28155-28163.

27. Loirand G, Pacaud P. The role of Rho protein signaling in hypertension. Nat Rev Cardiol. 2010;7(11):637-647.

28. Hirano K. Current topics in the regulatory mechanism underlying the $\mathrm{Ca}^{2+}$ sensitization of the contractile apparatus in vascular smooth muscle. J Pharmacol Sci. 2007;104(2):109-115.

29. Ghosh J, et al. The role of transforming growth factor $\beta 1$ in the vascular system. Cardiovasc Pathol. 2005;14(1):28-36.

30. Zacchigna L, et al. Emilin1 links TGF- $\beta$ maturation to blood pressure homeostasis. Cell. 2006;124(5):929-942.

31. August P, Suthanthiran M. Transforming growth factor $\beta$ signaling, vascular remodeling, and hypertension. NEngl J Med. 2006;354(25):2721-2723.

32. Pfeiffer A, Middelberg-Bisping K, Drewes C, Schatz H. Elevated plasma levels of transforming growth factor- $\beta 1$ in NIDDM. Diabetes Care. 1996;19(10):1113-1117.

33. Porreca E, et al. Increased transforming growth factor- $\beta$ production and gene expression by peripheral blood monocytes of hypertensive patients. Hypertension. 1997;30(1 pt 1):134-139.

34. Derhaschnig U. Increased levels of transforming growth factor- $\beta 1$ in essential hypertension. Am J Hypertens. 2002;15(3):207-211.

35. Daniel C. Blocking of angiotensin II is more than blocking of transforming growth factor- $\beta$. Kidney Int. 2008;74(5):551-553. 
36. Zhu S, Liu Y, Wang L, Meng QH. Transforming growth factor- $\beta 1$ is associated with kidney damage in patients with essential hypertension: renoprotective effect of ACE inhibitor and/or angiotensin II receptor blocker. Nephrol Dial Transplant. 2008;23(9):2841-2846.

37. Xu Z, et al. Pravastatin attenuates left ventricular remodeling and diastolic dysfunction in angiotensin II-induced hypertensive mice. J Cardiovasc Pharmacol. 2008;51(1):62-70.

38. Yurovsky VV, et al. Autocrine TGF- $\beta 1$ mediates angiotensin II-induced proliferative response of cerebral vessels in vivo. Am J Hypertens. 2007;20(9):950-956.
39. Argano $\mathrm{C}$, et al. Transforming growth factor $\beta 1$ T29C gene polymorphism and hypertension: relationship with cardiovascular and renal damage. Blood Press. 2008;17(4):220-226.

40. Li B, et al. TGF- $\beta 1$ DNA polymorphisms, protein levels, and blood pressure. Hypertension. 1999;33(1Pt2):271-275.

41. Niu W. Evaluation of transforming growth factor $\beta-1$ gene $869 \mathrm{~T} / \mathrm{C}$ polymorphism with hypertension: a meta-analysis. Int J Hypertens. 2011; 2011:934265.

42. Eiser AR. Does over-expression of transforming growth factor- $\beta$ account for the increased morbidity in African-Americans?: possible clinical study and therapeutic implications. Med Hypotheses. 2010;75(5):418-421.

43. Liu YH, et al. Role of inducible nitric oxide synthase in cardiac function and remodeling in mice with heart failure due to myocardial infarction. $A m \mathrm{~J}$ Physiol Heart Circ Physiol. 2005;289(6):2616-2623.

44. Shi J, Badri KR, Choudhury R, Schuger L. P311induced myofibroblasts exhibit ameboid-like migration through RalA activation. Exp Cell Res. 2006;312(17):3432-3442.

45. Taylor GA, Hudson E, Resau JH, Vande Woude GF. Regulation of P311 expression by Met-hepatocyte growth factor/scatter factor and the ubiquitin/proteasome system. J Biol Chem. 2000;275(6):4215-4219. 